\title{
VIOLÊNCIA CONTRAA MULHER: A EFICÁCIA DAS MEDIDAS PROTETIVAS DE URGÊNCIAA PARTIR DOS MUNICÍPIOS DA QUARTA COLÔNIA/RS
}

\author{
VIOLENCE AGAINST WOMEN: THE EFFECTIVENESS OF PROTECTIVE \\ EMERGENCY MEASURES FROM THE MUNICIPALITIES OF \\ THE FOURTH COLONY/RS
}

\author{
Luiza Rosso Mota $^{1}$ e Dandara Neuenfeldt Finkler ${ }^{2}$
}

\section{RESUMO}

A falta de estrutura e amparo após a decretação das medidas protetivas de urgência, no âmbito da violência doméstica e familiar contra mulher, aumenta a vulnerabilidade das vítimas, especificamente, em um período desafiador de isolamento em razão da Pandemia de Covid-19. Tendo-se como base os municípios da Quarta Colônia, Região Central do Estado do Rio Grande do Sul, questiona-se: a falta de estrutura e amparo após a decretação de medidas protetivas de urgência tornam as vítimas ainda mais vulneráveis, perpetrando uma lógica de violência continuada por parte dos agressores? Como objetivo geral, buscou-se analisar se a falta de estrutura e amparo após a decretação de medidas protetivas de urgência tornam as vítimas ainda mais vulneráveis, perpetrando uma lógica de violência continuada por parte dos agressores. Foram utilizados os métodos de abordagem dialético, de procedimento monográfico e das técnicas bibliográficas e de questionário A relevância da pesquisa reside na insegurança das mulheres em diversos contextos, notadamente, quando o principal obstáculo é enfrentar suas próprias crenças e medos. Mulheres são agredidas, torturadas e mortas dia após dia por seus companheiros e, se não bastasse, sentem na alma as injustiças de uma sociedade ainda patriarcal, sem estrutura para a sua proteção. As medidas protetivas de urgência acabam oferecendo uma falsa segurança e uma ilusão de proteção às vítimas a partir dos estudos demonstrados e a violência continuada é maquiada pelas subnotificações.

Palavras-Chave: doméstica, Estado, insegurança, vítima, vulneráveis.

\section{ABSTRACT}

The lack of structure and protection after the enactment of emergency protective measures, within the scope of domestic and family violence against women, increases the vulnerability of the victims, specifically, in a challenging period of isolation due to the Covid-19 Pandemic. Based on the municipalities of the Fourth Colony, Central Region of the State of Rio Grande do Sul, the question arises: the lack of structure and protection after the decree of emergency protective measures make the victims even more vulnerable, perpetrating a

\footnotetext{
${ }^{2}$ Advogada Criminalista e Ambiental - OAB/RS 90.533. Docente do Curso de Direito da Antonio Meneghetti Faculdade (AMF) e da Faculdade Palotina (FAPAS). Doutoranda no Programa de Pós-Graduação em Direito da Faculdade Nacional de Direito da Universidade Federal do Rio de Janeiro (UFRJ), com ênfase em Teorias da Decisão, Interpretação e Justiça, e pesquisa na área processual penal e criminológica. Mestra em Direito pela Universidade Federal de Santa Maria (UFSM), com ênfase em Direitos Emergentes da Sociedade Global e Direitos da Sociobiodiversidade e Sustentabilidade. Especialista em Direito Público com ênfase em Gestão Pública. Foi professora substituta do Curso de Direito da Universidade Federal de Santa Maria, nas disciplinas de direito penal, processo penal e estágio prático penal - 2015/2017 (UFSM). Integrante da Comissão de Educação Jurídica da Seccional Rio Grande do Sul. Integrante da Comissão da Advocacia Criminal e da Comissão Especial de Direito Ambiental, Subseção Santa Maria/RS. E-mail: luiza_mota@yahoo.com.br. Lattes: http://lattes.cnpq.br/6652478222518839. Orcid iD: https://orcid.org/0000-0002-9041-7314

${ }^{3}$ Discente do $10^{\circ}$ semestre do Curso de Direito da Faculdade Antonio Meneghetti (AMF). Estagiária na $1^{a}$ Vara Judicial da Comarca de Agudo/RS. E-mail: dandsfinkler@gmail.com
} 
logic of continued violence by aggressors? As a general objective, we sought to analyze whether the lack of structure and protection after the enactment of emergency protective measures make victims even more vulnerable, perpetrating a logic of continued violence on the part of the aggressors. The methods of dialectical approach, monographic procedure and bibliographic and questionnaire techniques were used. The relevance of the research resides in the insecurity of women in different contexts, especially when the main obstacle is to face their own beliefs and fears. Women are beaten, tortured and killed day by day by their companions and, if that were not enough, they feel in their souls the injustices of a society still patriarchal, with no structure for their protection. Emergency protective measures end up offering false security and an illusion of protection to victims based on the studies shown and the continued violence is made up by underreporting.

Keywords: domestic, state, insecurity, victim, vulnerable.

\section{INTRODUÇÃO}

O mundo encontra-se em constante transformação e as ciências sociais também têm um papel significativo na construção de uma sociedade que seja capaz de enfrentar os problemas coletivos e dar respostas aos anseios de forma digna, humana e eficaz. Nesta perspectiva, o presente texto parte de um recorte vinculado à luta feminina no combate à violência de gênero, em especial, a violência doméstica e familiar contra mulher, buscando ampliar os espaços de diálogos a partir das transformações sociais.

Percebe-se que os órgãos jurisdicionais não estão devidamente preparados para proteger inteiramente a vida das mulheres. Ressalta-se, ainda, que não são apenas as mulheres que sofrem de violência doméstica, pois esta prática também é uma realidade vivida por inúmeras famílias, pessoas vulneráveis, crianças e adolescentes, dentro de diversos lares.

A falta de estrutura e amparo após a decretação das medidas protetivas de urgência, no âmbito da violência doméstica e familiar contra mulher, aumenta a vulnerabilidade das vítimas, especificamente, em um período desafiador de isolamento em razão da Pandemia de Covid-19. Além da possibilidade de violência continuada por parte dos agressores, há inúmeros casos de violência doméstica que passam a se tornar letais em relação à ineficácia das medidas protetivas, seja pelas dificuldades das mulheres após a realização das denúncias seja pelas subnotificações em razão de medos e ameaças.

A violência contra a mulher aumentou significativamente e as mortes estão relacionadas, em grande parte, a uma forma de represália por parte dos agressores. Assim, tendo-se como base os municípios da Quarta Colônia, Região Central do Estado do Rio Grande do Sul e para fins de delineamentos da pesquisa, questiona-se: a falta de estrutura e amparo após a decretação de medidas protetivas de urgência tornam as vítimas ainda mais vulneráveis, perpetrando uma lógica de violência continuada por parte dos agressores?

Neste contexto, busca-se, como objetivo geral, analisar se a falta de estrutura e amparo após a decretação de medidas protetivas de urgência tornam as vítimas ainda mais vulneráveis, perpetrando uma lógica de violência continuada por parte dos agressores. A pesquisa objetiva especificamente contextualizar a luta das mulheres contra a violência, descrever sobre a Lei Maria da Penha e as 
medidas protetivas de urgência, bem como discorrer sobre a falsa segurança e a ilusão de proteção das medidas protetivas de urgência sobre um contexto em movimento e de isolamento, a partir dos resultados obtidos por meio dos questionários aplicados.

A pesquisa desenvolve-se a partir do método dialético, discorrendo as contradições existentes entre a luta das mulheres, a legislação e a real proteção às vítimas. A luta das mulheres contra a violência será apresentada, no texto, como pretensão da verdade dentro da perspectiva de tese. A antítese será estabelecida pela abordagem da Lei Maria da Penha, no sentido de contrapor à luta das mulheres, não na sua esfera negativa, mas no ponto de resolver o problema da violência. Em um terceiro momento, apresenta-se a síntese a partir da junção das ideias trabalhadas, consistente no resultado do confronto entre a tese e a antítese, abordando o estudo dos questionários aplicados em relação à vulnerabilidade das vítimas diante de uma falsa proteção. Além disso, utiliza-se do método de procedimento de estudo de caso ou monográfico, pois realiza-se uma investigação por meio de questionário virtual, a fim de identificar sobre as medidas protetivas de urgência, após a decretação, no âmbito da violência doméstica e familiar contra mulher. O público alvo foram mulheres residentes e domiciliadas na Região da Quarta Colônia, situada no interior do Rio Grande do Sul, mais precisamente na região central do Estado, composta por nove municípios, sendo eles, Agudo, Dona Francisca, Faxinal do Soturno, Ivorá, Nova Palma, Pinhal Grande, Restinga Seca, São João do Polêsine, Silveira Martins.

A técnica de pesquisa se caracteriza por ser bibliográfica, pois o estudo será desenvolvido a partir de livros, doutrinas, artigos científicos etc. Ainda, se caracteriza pela técnica de questionário, pois foram elaboradas perguntas específicas sobre a pesquisa. $\mathrm{O}$ questionário online foi disponibilizado às mulheres, de forma virtual, com divulgação pessoal e virtual -essa última através da rede social Facebook-. Por oportuno, destaca-se, também, que a presente pesquisa de questionário, está em consonância com a Resolução n. 510/2016, artigo 1º parágrafo único, inciso $V^{3}$, do Conselho Nacional de Saúde.

A relevância da pesquisa reside na insegurança das mulheres em diversos contextos, notadamente, quando o principal obstáculo é enfrentar suas próprias crenças e medos. Mulheres são agredidas, torturadas e mortas dia após dia por seus companheiros e, se não bastasse, sentem na alma as injustiças de uma sociedade ainda patriarcal, sem estrutura para a sua proteção.

As medidas protetivas de urgência têm o condão de proteger as vítimas de violência doméstica de seus agressores, e por regra, deveriam assegurar a sobrevivência dessas mulheres que se encontram em situação de vulnerabilidade. Entretanto, o cenário é no mínimo intrigante, e faz perceber que o Estado não está preparado para lidar com esse tipo de situação. As medidas adotadas são imaturas e inconsistentes. Justifica-se, uma vez que a principal medida adotada em caso de descumprimento

\footnotetext{
${ }^{4}$ Art. $1^{\circ}$. Esta Resolução dispõe sobre as normas aplicáveis a pesquisas em Ciências Humanas e Sociais cujos procedimentos metodológicos envolvam a utilização de dados diretamente obtidos com os participantes ou de informações identificáveis ou que possam acarretar riscos maiores do que os existentes na vida cotidiana, na forma definida nesta Resolução. Parágrafo único. Não serão registradas nem avaliadas pelo sistema CEP/CONEP:

$\mathrm{V}$ - pesquisa com bancos de dados, cujas informações são agregadas, sem possibilidade de identificação individual;
} 
das medidas protetivas de urgência pelo agressor, é a privação da sua liberdade, que não impede a continuidade da violência, pois as vítimas podem ser mortas antes da efetivação da medida.

O presente texto estruturou-se em três capítulos, em um primeiro momento discorre-se sobre a luta das mulheres contra a violência, no segundo capítulo aborda-se a respeito da Lei Maria da Penha e as medidas protetivas de urgência. Ao final, discorre-se em relação à falsa segurança e a ilusão de proteção das medidas protetivas de urgência a partir de um contexto em movimento e de isolamento, diante dos resultados obtidos por meio do questionário online disponibilizado.

\section{A LUTA DAS MULHERES CONTRA A VIOLÊNCIA}

Ao longo da história, os casos de violência intrafamiliar eram considerados normais, tendo como foco a figura da mulher, posto que a família surgiu submissa ao pátrio poder, o qual possuía todos os direitos sobre a vida da esposa e dos filhos. Tal violência chegou a ser considerada banal e legal, a ser suportada pela mulher sem direito de queixa. Na idade média, por exemplo, a mulher poderia ser punida pelo marido caso exercesse um comportamento por ele considerado inadequado ou pela simples pretensão de reivindicar a sua superioridade. Tais atos eram considerados legais, desde que não quebrassem ossos ou deixassem hematomas no rosto da esposa (VASCONCELOS; RESENDE, 2018, p. 121).

De acordo com Carneiro e Fraga (2012, p. 370), o contexto histórico brasileiro é determinante quando se aborda a questão da violência contra a mulher, pois no decorrer da história a mulher carregou o estigma de sujeito frente ao homem. Este fator condiciona os dias atuais, uma vez que foi construído na sociedade, de forma cultural.

A violência tem a ver com uma forma de abuso de poder, aliado ao meio inadequado de resolução de conflitos, que inúmeras vezes a mulher é silenciada. Além disso, é uma tarefa muito árdua romper com a cultura enraizada de um sistema que exalta a soberania masculina (RÉGIS; CORDEIRO, 2015, p. 28).

Neste contexto, Sabadell refere que

A intimidade é um grave problema para as mulheres em sociedades machistas como a nossa. Em culturas machistas, o mais comum é que o homem hetero considere o espaço privado como um local de sua dominação. Homens podem brigar e até se matar nas ruas, mas com as mulheres, o que fazem é agredi-las no lar; na esfera privada (2020, p. 15 e 16).

Com efeito, muitas mulheres que sofrem de violência doméstica, nem sequer percebem a gravidade do problema que estão vivenciando, uma vez que a maioria se encontra imersa nas tramas e conjunturas de uma sociedade culturalmente patriarcal. A percepção que possuem sobre violência, em geral, se condiciona à lógica de aceitação passiva, advinda de cresças e valores, o que torna ainda mais imprescindível desmistificar a naturalidade da violência do homem contra a mulher para que elas possam denunciar (COSTA et al., 2014, p. 179). 
Esta naturalização se dá em razão da ideologia romântica que as mulheres possuem sobre a família, de que a família deve viver em harmonia. E para a efetivação da harmonia familiar, muitas vezes, há um processo de naturalização da ofensa verbal, ou seja, para muitos homens é "normal" ofender verbalmente a mulher, tratá-la como propriedade, haja vista que em suas concepções é o homem quem tem o dever de manter a família. Consequentemente, o problema está na demora da vítima em perceber que está sendo violentada e assim já ter se agravado a situação para uma violência física (VASCONCELOS; RESENDE, 2018, p. 124).

Cunha (2014, p. 150) dispõe que a violência contra a mulher é um fenômeno antigo e assim muito banalizado, que foi justificado por comuns pressupostos biológicos. Esses apontam a mulher como ser mais frágil, de menor força física e capacidade racional que o homem, tendo em sua própria natureza a característica domesticável, que leva a tendência de ser dominada, uma vez que existe a necessidade de ser protegida e orientada por alguém. Nesta perspectiva, ela se encontrava passível de violência. Esta naturalização da violência de gênero se desloca para todos os tempos históricos como um fenômeno que sempre existiu e que continuará existindo, mesmo que em menor potencialidade. É preciso, portanto, descontruir essa concepção natural para que se possa ter um progresso significativo, a fim de coibir de vez a violência praticada contra o gênero feminino.

O fenômeno da violência doméstica perpetua por um abismo de impunidade, provocado pelo silêncio das vítimas. Este parâmetro está baseado no número real de mulheres que sofrem algum tipo de violência diariamente, sem que sejam levadas a registro nas Delegacias de Defesa da Mulher ou tampouco chegam a conhecimento do poder Judiciário. Os reflexos se dão por vários motivos, mas o medo de sofrer represálias por parte do agressor, o envolvimento afetivo, a dependência financeira e o receio de ficar sozinha, são os mais constatados nestes casos. Estes aspectos contribuem para que os agressores continuem praticando os mesmos delitos e, comumente, contra as mesmas mulheres, mantendo um círculo diário de violência (MOURA, 2015, p. 40).

A relação de poder que o homem exerce sobre a mulher é uma forma de violência, estimulando a dominação e a discriminação e, consequentemente, um problema a ser enfrentado. Historicamente, o homem sempre foi o sexo dominante e responsável pelo sustento do lar. A mulher por sua vez, foi domesticada a procriação, a manutenção da casa e a educação dos filhos, tudo sob a supervisão e subordinação do marido (RÉGIS; CORDEIRO, 2015, p. 25). Na atual sociedade, a hegemonia cultural significa que "aceitar uma visão da realidade específica dum grupo dominante é considerado como sendo normal no enquadramento da ordem natural das coisas, mesmo por quem, na realidade, lhe está subordinado" (DAHL, 1993, p. 6).

Todavia, essa naturalização da opressão e da discriminação passou-se a ser questionada pelas mulheres, dando-se início a uma série de movimentos, reflexões, ações de resistência e produções literárias. Foram surgindo vários grupos feministas para discutir sobre a sexualidade e a literatura relacionada às mulheres (COSTA et al., 2014, p. 178-179). 
As mulheres conquistaram grandes avanços na sociedade e, atualmente, ocupam um papel de destaque social, notadamente, quando lutam para terem seus direitos assegurados. Um exemplo concreto é a Lei n. ${ }^{\circ} 11.340 / 06$, instituída no intuito de mudar o cenário de violência contra as mulheres, punindo com maior rigor os agressores e protegendo as vítimas do contexto de violência (RÉGIS; CORDEIRO, 2015, p. 28).

De acordo com Vasconcelos e Resende (2018, p. 125), mesmo após décadas de luta, há um longo caminho a ser percorrido no cenário histórico e cultural da mulher. Além disso, os índices de violência praticados contra as mulheres são altíssimos frente ao avanço do século. A luta é diária para a conquista do espaço, da igualdade e do respeito da mulher na sociedade.

Na realidade, além de administrarem a vida doméstica e disputarem vagas no mercado de trabalho, as mulheres precisam, ainda, conquistar legitimidade e respeito social tanto em casa, perante o companheiro, quanto na comunidade em que vivem (BIAGI, 2014, p. 10). Portanto, há necessidade de uma consciência crítica para compreender os males e criar condições de combatê-los, identificando as condições e os anseios desejáveis (DAHL, 1993).

A luta das mulheres sinalizou muitas conquistas ao longo dos anos, máxime, a partir dos movimentos feministas. Os espaços de diálogos sobre questões de gênero foram ampliando em detrimento de uma história silenciada de violência contra mulher. Nesta conjuntura, se insere a criação e vigência da Lei Maria da Penha, conforme exposto na sequência.

\section{LEI MARIA DA PENHA E AS MEDIDAS PROTETIVAS DE URGÊNCIA}

A Lei Maria da Penha advém de um contexto histórico de luta, assim como os direitos que as mulheres conquistaram ao longo dos anos, pois perpassam por um cenário de impunidade e violência dentro do âmbito doméstico e familiar. A predominância de uma sociedade machista e culturalmente patriarca são aspectos relevantes quando se busca mudar o futuro das mulheres. E a conquista de uma lei protetora e salvadora, a qual tem o objetivo de resguardar a vida e as condições de como todas as mulheres merecem vivê-la, é um grande marco na história da mulher brasileira.

Salgado, Kreuz e Bertotti (2018, p. 257-258) contextualizam essa conjuntura de conquista e violência contra a mulher quando abordam o porquê desta denominação "Lei Maria da Penha". A lei foi criada a partir da história de duas tentativas de morte sofridas pela farmacêutica brasileira, Maria da Penha Maia Fernandes, praticadas pelo seu esposo, um professor colombiano. Na primeira oportunidade, ela foi vítima de uma simulação de assalto e na segunda, ele buscou eletrocutá-la durante o banho. Das agressões, Maria da Penha Maia Fernandes ficou paraplégica. Após 19 anos dos acontecimentos, o agressor foi preso, sendo condenado a 08 anos de prisão. Neste contexto, quando a Comissão Interamericana de Direitos Humanos tomou conhecimento dos fatos, reconheceu o 
ocorrido como o primeiro crime doméstico e condenou o Brasil que, devido às pressões nacionais sofridas, editaram e publicaram a Lei no 11.340/2006, conhecida como a Lei Maria da Penha.

Desta forma, entrou em vigência uma nova legislação penal cujo objetivo é coibir a violência doméstica contra a mulher e estabelecer punições aos agressores. O texto legal evidencia uma preocupação intencionada de proteção à mulher, abrangendo classe, raça, etnia, orientação sexual, renda, cultura, nível educacional, idade e religião. A mulher passou a ter maior proteção no sentido de não ter que viver com violência, preservando sua saúde física e mental e seu aperfeiçoamento moral, intelectual e social. Ainda, lei conta com várias políticas públicas preventivas, como a integração operacional de agentes e instituições estaduais, e visa que todo o contexto da vida doméstica da mulher passe por melhorias, especialmente, que ela se sinta em segurança e mantenha a sua integridade física e dignidade (SALGADO; KREUZ; BERTOTTI, 2018, p. 258).

Embora não seja bem compreendida e constantemente associada ao aumento de punibilidade, é um marco legal de prevenção. A legislação visa assegurar às mulheres o direito fundamental de viver uma vida livre de violência. Para garantir esse direito de forma eficiente, instituiu no ordenamento jurídico a violência qualificada como doméstica ou familiar, a violência contra a mulher e a violência de gênero, trazendo mudanças significativas (BIAGI, 2014, p. 10).

A criação da Lei Maria da Penha pode ser vista como um grande avanço, no sentido de que a violência que ocorre entre as relações familiares e de afeto deixou de ser abordada como um problema privado, em que a impunidade e a violência prevaleciam. Outro ponto a ser destacado é a agilidade na análise dos casos que envolvem violência doméstica e familiar contra a mulher, assim como as providências tomadas conforme cada situação. Isso significa que, no momento da notícia crime ou do registro de ocorrência, quando envolver violência doméstica e familiar, em conformidade com o Lei n. ${ }^{\circ}$ 11.340/06, o Delegado de Polícia irá adotar procedimentos que divergem dos demais crimes, uma vez que a lei determina especificadamente as providências legais cabíveis a serem adotadas pela autoridade policial e seus agentes (CARNEIRO; FRAGA, 2012, p. 378-379).

Ao identificar prática efetiva ou eminência de violência doméstica contra a mulher, o Delegado de Polícia deve seguir o procedimento disposto nos artigos 10 a 12 da Lei n. ${ }^{\text {o }}$ 11.340/06. Dentre as providências previstas na lei, os policiais deverão agir para garantir proteção da vítima, comunicar o fato de imediato ao Ministério Público e ao Poder Judiciário, encaminhar a vítima ao hospital, posto de saúde, ou Instituto Médico Legal; e fornecer transporte e abrigo à vítima e seus dependentes quando houver risco de vida (BRASIL, 2006, s.p.).

Com a introdução da Lei Maria da Penha e aliada ao novo comportamento do Estado, as vítimas passaram a se sentir mais seguras, em certa medida, justamente por estarem amparadas pelo rol de medidas protetivas, as quais buscam protegê-las de todo tipo de violência. Estas medidas foram elaboradas pelo legislador com base nas experiências vivenciadas decorrentes das formas 
e atitudes na prática dos crimes cometidos no âmbito da violência doméstica e familiar (RÉGIS; CORDEIRO, 2015, p. 36).

As medidas protetivas de urgência foram introduzidas pela Lei $n^{\circ}$ 11.340/06 como forma de enfretamento à violência doméstica e familiar contra a mulher, inovando o aspecto protetivo acentuado. Essas medidas trouxeram mudanças legislativas substanciais e a decretação crescente em favor de mulheres, vítimas de violência doméstica evidenciou, significativamente, a violência contra a mulher (MOURA, 2015, p. 36).

Com o amparo legal, as vítimas começaram a denunciar a violência praticada por seus companheiros e pessoas com as quais conviviam em âmbito doméstico ou familiar. Assim, a violência que antes era cometida de forma silenciosa, passou a ser vista no mundo jurídico e social, perpetuando um sentimento de espanto e repúdio frente ao elevado número de casos que vieram à tona.

A Lei Maria da Penha dispõe distintas possibilidades de medidas protetivas com o objetivo de garantir, da melhor forma possível, a proteção da mulher que se encontrar frente à violência doméstica. Tais medidas podem ser aplicadas após a denúncia de agressão feita pela vítima à Delegacia de Polícia. O juiz tem até 48 horas após o recebimento do pedido da vítima ou do Ministério Público para determinar a execução destes mecanismos, entre eles, o afastamento do agressor do lar em que ele e a vítima conviviam, a fixação de um limite mínimo de distância entre ambos, passando pela restrição do porte ou suspensão da posse de armas de fogo, as medidas envolvem prevenção e também certa forma de punição do agressor. O objetivo principal das medidas, é evitar que a situação se repita e, para isso, o afastamento do contato do agressor com a vítima é medida essencial (SALGADO; KREUZ; BERTOTTI, 2018, p. 260-261).

Com as medidas, o Estado busca prevenir qualquer ação violenta do agressor, e também garantir à vítima uma tutela jurisdicional que pode ser requerida a qualquer momento do processo. Além disso, separou as medidas em dois tópicos, as medidas que amparam a ofendida e as que obrigam o agressor. Assim, Vasconcelos e Resende (2018, p. 125) referem que "o Estado, então, busca prevenir qualquer ação violenta do agressor, antes de ocorrer o ato e durante o caminhar do processo (caso em que já tenha cometido agressão), assim como garantir à vítima uma tutela jurisdicional que pode ser requerida em qualquer fase deste processo".

Para que sejam concedidas as medidas de proteção é necessária a presença da verossimilhança no depoimento da vítima e que seja reconhecido o fumus bonis iuris, que no âmbito criminal é mais conhecido como fumus comissi delicti, ou seja, presença de materialidade delitiva e indícios suficientes de autoria, para a concessão de medidas protetivas. Outro ponto, é o reconhecimento do periculum in mora ou periculum libertatis, que é compreendido como o perigo da demora, em que o atraso no deferimento das medidas cautelares poderá lesionar a ofendida (CAVALCANTE; RESENDE, 2014).

Na maioria das vezes, não se tem testemunhas oculares que presenciam a violência cometida em ambiente doméstico ou familiar, justamente por ser praticada de forma clandestina, pois geralmente 
ocorre dentro de casa, entre "quatro paredes e portas fechadas". Por este motivo, a palavra da vítima tem grande relevância no julgamento, podendo ensejar prova suficiente para a condenação desde que seja coerente com dos demais elementos do processo.

Além disso, o descumprimento das medidas de proteção é fundamento suficiente para o pedido de prisão preventiva do ofensor, desde que presentes os seus pressupostos, como já referido acima, fumus comissi delicti e periculum libertatis. Este descumprimento está previsto em uma das hipóteses de admissibilidade da prisão preventiva, consoante art. 313, III, do Código de Processo Penal (BRASIL, 1941), assegurando maior garantia e proteção às vítimas de violência doméstica e familiar.

De acordo com Biagi (2014, p. 27), os casos de violência voltam a se repetir mesmo que a vítima esteja amparada pelas medidas protetivas e que ela leve adiante a denúncia da agressão por parte do autor Isso porque fica na dependência da mulher registrar o descumprimento, já que não existem outros meios de averiguar. O descumprimento da medida protetiva só é verificado se a vítima comparecer na Delegacia de Polícia e comunicar o fato. Ocorre que, na realidade, o descumprimento vem acompanhado de outro crime, não sendo apenas caso de desobediência judicial.

Essas medidas de proteção sem dúvidas representam o maior avanço introduzido pela Lei Maria da Penha, mas existem alguns obstáculos para que sejam aplicadas de forma mais efetiva. Entre os obstáculos estão aqueles de natureza operacional, como a falta de regulamentação de procedimentos integrados às políticas institucionais e a inadequação de procedimentos administrativos e burocráticos. Também, encontram-se presentes àqueles relacionados à criação de políticas, serviços e mecanismos para dar maior eficácia as medidas protetivas de urgência, bem como a falta de profissionais capacitados para atender ao volume de procedimentos relacionados aos crimes dessa natureza, o que, de certa forma, impede que a aplicação dessas medidas protetivas ultrapasse o aspecto formal (PASINATO et al., s.a., p. 237).

Assim, ainda que exista esse amparo da legislação preocupando-se com a proteção da mulher, preponderam lacunas quanto às medidas protetivas. Isso porque vêm se mostrando ineficaz depois da sua concessão, não protegendo a vítima de violência doméstica, conforme previsto pelo legislador (RÉGIS; CORDEIRO, 2015, p. 36).

Com efeito, o Estado, ainda desestruturado para atender as mulheres vítimas de violência, não se move com a emergência necessária, gerando um certo descrédito por parte das vítimas e uma confiança na impunidade por parte dos agressores (BIAGI, 2014, p. 22). A falta de fiscalização do Estado quanto às medidas protetivas de urgência, pode ser considerada um exemplo, considerando que, em algumas situações, por meio de ameaças, o agressor obriga a vítima a se retratar da representação para que a medida seja revogada.

Nos dias atuais, a violência contra mulher é marcada pelo período de isolamento decorrente da pandemia de Covid-19, já que muitas mulheres passarão mais tempo dentro do lar com seus companheiros. Esta afirmação encontra amparo no Anuário Brasileiro de Segurança Pública de 2019, 
considerando que $88,8 \%$ das mulheres são vítimas de violência doméstica por parte dos seus companheiros ou ex-companheiros (BRASIL, 2019). Sob este ponto de vista, Sabadell (2020, p. 15) afirma que "hoje chega o coronavírus e sua invisibilidade se torna o cumplice ideal do machismo brasileiro".

Observa-se que o Estado está se adaptando a uma legislação ainda recente, diante de uma história sinalizada pelo modelo machista, advindo da dominação masculina sob os corpos femininos. Ainda, há um longo caminho de estudos, pesquisas e práticas a ser conquistado em relação aos direitos e proteção da mulher perante a sociedade, consoante será demonstrado a seguir.

\section{A FALSA SEGURANÇA E A ILUSÃO DE PROTEÇÃO DAS MEDIDAS PROTETIVAS DE URGÊNCIA A PARTIR DE UM CONTEXTO EM MOVIMENTO}

A Lei 11. 340/06, popularmente conhecida como Lei Maria da Penha (BRASIL, 2006), de fato modificou o cenário da violência doméstica e familiar contra a mulher, fazendo com que muitos agressores fossem punidos e também muitas vítimas fossem salvas. O que antes era uma situação comum e não tinha nenhuma consequência séria, uma vez que era regulamentada pelo direito privado, perpetuando uma continua vivência de impunidade e violência ao longo dos relacionamentos passou a ser vista com outros olhos no meio social. Contudo, ainda se tem inúmeros casos de violência doméstica e familiar que não são levados a conhecimento do Poder Judiciário, notadamente, em períodos de transformações sociais. As subnotificações aumentam em períodos de isolamento social ou confinamento, tendo em vista que "o lugar mais perigoso para a tutela da integridade feminina é o lar" (SABADELL, 2020, p. 15).

Além disso, as vítimas desta violência têm medo de sofrer represálias por parte de seus agressores após o registro do boletim de ocorrência e acabar piorando a situação. Inclusive, muitas mulheres não tem para onde ir, ficando abrigadas nas casas de familiares. Contudo, esta única opção pode se tornar sinônimo de humilhação, em razão de expor a situação para os familiares, de invadir a rotina desses, da dificuldade em manter o sustento próprio e dos filhos. São reflexos que podem levar a mulher a retornar o convívio com o agressor.

Outro fator significativo que, ainda existe, é a insegurança de que o Estado não se moverá com a emergência necessária para impedir a continuidade da violência, uma vez que só terá conhecimento do descumprimento das medidas protetiva de urgência se a própria vítima comunicar a desobediência judicial por parte do agressor. Neste percurso, o quadro violento poderá ser irreversível.

Deste modo, com o objetivo de se verificar se a falta de estrutura e amparo após a decretação das medidas protetivas de urgência, no âmbito da violência doméstica e familiar contra mulher, aumenta a vulnerabilidade das vítimas, sob uma lógica de violência continuada por parte dos agressores, foram analisados dados colhidos em questionário virtual direcionado às mulheres da Quarta Colônia/ RS, situada na região central do Estado, obtendo-se 71 participações. O questionário online foi disponibilizado, de forma virtual, com divulgação física e virtual, via a rede social Facebook. 
Inicialmente, questionou-se quais as espécies de violência sofridas pelas mulheres, constatando que $47 \%$ das mulheres sofreram violência psicológica, 28\% sofreram ameaças e $25 \%$ violência física.

Gráfico 1 - Violências sofridas por Mulheres.

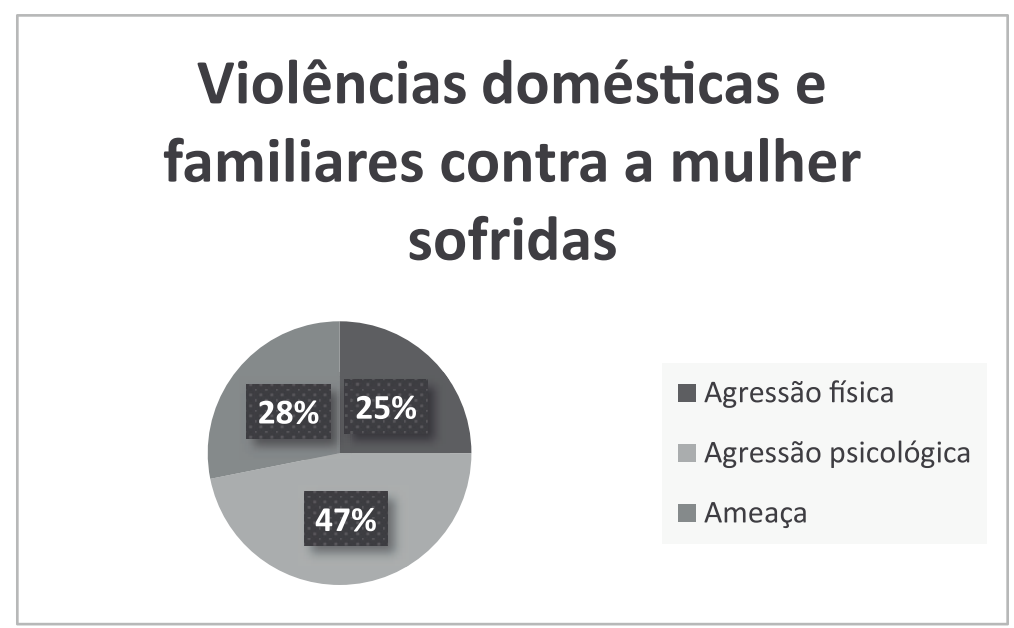

Fonte: Dados da pesquisa.

Diante do demonstrativo, percebe-se que existe um grande número de mulheres que foram vítimas de violência doméstica e familiar, predominando como a mais sofrida entre as mulheres, a violência psicológica. Importante destacar que a porcentagem relativa às mulheres que sofreram agressão física é consideravelmente significativa, ratificando não só o poder de posse por parte do agressor, mas a propriedade e o desrespeito sobre o corpo da mulher.

Em um segundo momento, foi questionado se as mulheres já haviam realizado registro de ocorrência em razão de terem sofrido violência. Neste ponto, os dados colhidos foram surpreendentes, uma vez que apenas $7 \%$ das mulheres que participaram da pesquisa, registram ocorrência contra o agressor, conforme se vislumbra no gráfico 2.

Gráfico 2 - Mulheres que registraram ocorrência contra o agressor.

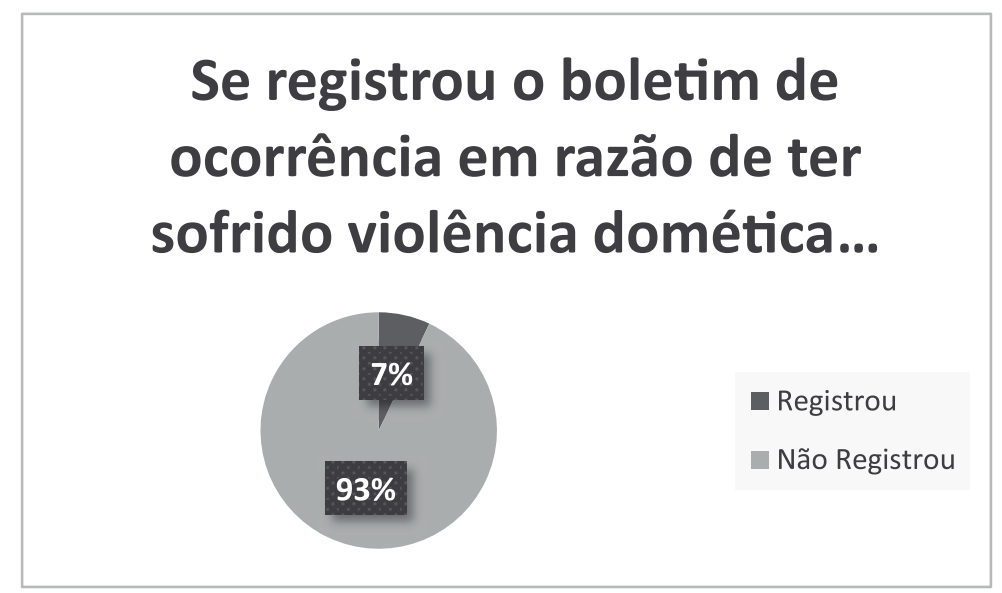

Fonte: Dados da pesquisa. 
Esse quadro demonstra que, embora as vítimas tenham sofrido violência doméstica e familiar, a maior parte não registrou o boletim de ocorrência. Os dados acima demonstram o número elevado de subnotificações no âmbito da violência doméstica e familiar contra a mulher. De fato, infere-se que o medo e a subjugação decorrente das raízes do patriarcado ainda imperam sobre as mulheres.

Aliás, "o silêncio se constitui como uma espécie de manto sagrado do machismo brasileiro; na verdade, o integra. O silêncio sempre foi cúmplice dos homens violentos que estupram, batem, humilham e, em muitos casos, matam suas mulheres [...]" (SABADELL, 2020, p. 14). Para uma correta avaliação do direito é essencial analisar as consequências desse para os indivíduos, pois o "silêncio acentua ainda mais a desigualdade e a injustiça" (DAHL, 1993, p.3).

Também, a pesquisa objetivou averiguar se as vítimas de violência doméstica e familiar se sentiam mais seguras por parte do Estado, após a decretação das medidas protetivas de urgência, sendo evidenciado, segundo os dados constantes no gráfico 3 , que $60 \%$ das mulheres se sentem mais seguras.

Gráfico 3 - Segurança ou insegurança da mulher após as medidas protetivas de urgência.

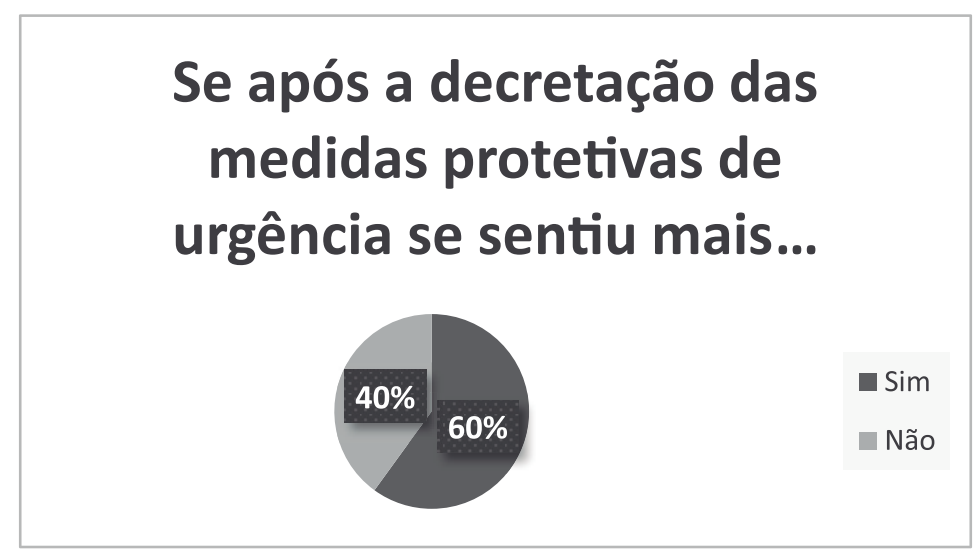

Fonte: Dados da pesquisa.

Pela análise do gráfico, verifica-se que as mulheres vítimas de violência se sentem mais seguras quando existe a proteção do Estado, por meio das medidas protetivas de urgência decretadas pelo judiciário. Contudo, $40 \%$ das mulheres demonstraram que, mesmo buscando e obtendo o deferimento de medidas protetivas, se sentem inseguras, confirmando, de certa forma, que há uma ilusão de proteção ou uma falsa segurança, já que $40 \%$ é um número muito significativo. Ou seja, uma porcentagem relativamente alta considerou não estar segura, ratificando o entendimento de que as vítimas se tornam ainda mais vulneráveis, após as medidas.

Por oportuno, é fundamental destacar que, na prática, as leis não modificam as subjetividades, sem aliar-se a um contexto de educação, de relações de solidariedade, de práticas responsáveis e de dignidade, inclusive, por parte dos atores jurídicos. Com a observância deste conjunto, as decisões são tomadas por indivíduos comprometidos com as vulnerabilidades humanas (PALACIO, 2015). 
Neste contexto, faz-se, ainda, primordial destacar que segundo os dados do Anuário Brasileiro de Segurança Pública, os feminicídios ${ }^{4}$ correspondem a 29,6\% dos homicídios dolosos de mulheres em 2018. Foram analisadas denúncias oferecidas pelo Ministério Público de mortes violentas de mulheres e constaram que "apenas $4 \%$ das vítimas tinham registrado boletim de ocorrência contra o agressor e que 3\% tinham medida protetiva" (BRASIL, 2019). Ou seja, a lógica de violência continuada por parte do agressor após a decretação de medidas protetivas, acaba sendo maquiada em decorrência das subnotificações, pois somente chega ao Poder judiciário quando a vítima já está silenciada pela morte, consoante se observa pelos índices de feminicídio.

Neste sentido, considerando o período de isolamento social decorrente da pandemia de Covid-19, no âmbito da violência doméstica e familiar contra a mulher, Sabadell reconhece as consequências do isolamento para as subnotificações, afirmando que

\begin{abstract}
neste momento em que se pensa na invisibilidade de um vírus que se une -e não só simbolicamente- à invisibilidade feminina em face da violência de gênero, cabe-nos uma séria reflexão. O que significa, em termos práticos, o confinamento em casa quando se convive com a violência de gênero no lar? Eu lhes digo, em primeiro lugar, aumento da subnotificação (2020, p. 15)
\end{abstract}

Com base nos municípios da Quarta Colônia, Região Central do Estado do Rio Grande do Sul, constata-se que a falta de estrutura e amparo após a decretação de medidas protetivas de urgência tornam as vítimas mais vulneráveis. De outro lado, observa-se a existência de uma violência continuada por parte dos agressores, que acaba sendo maquiada em razão das subnotificações. Isso porque há um número bastante elevado de feminicídios e os dados revelam um número muito baixo de registros de ocorrência contra o agressor, por parte destas mulheres mortas.

Diante desses dados, restou visível que a violência doméstica ou familiar ainda predomina frente à legislação e o amparo Estatal, uma vez que existe um fator invisível aos olhos do Estado, movido por medos e crenças, fazendo com que as vítimas fiquem em silêncio. Embora as vítimas se sintam, em parte, protegidas pelas medidas protetivas de urgência, essas não são eficazes, uma vez que o Estado não monitora o descumprimento, tampouco possui estrutura para abrigá-las, de forma segura, ficando estas na dependência do amparo de familiares e contando com a sorte de não serem surpreendidas, pois muitas vezes o agressor consegue se reaproximar e cometer uma violência ainda mais grave, quando não comete a morte da vítima.

Em suma, a decretação das medidas protetivas de urgência tem o condão de afastar o agressor da presença da vítima e assim coibir a prática da violência. No entanto, considerando o domínio que o autor tem sobre a vítima, dada uma construção de afeto, confiança, respeito e também a relação familiar, faz com que facilite o contato com esta. A proteção pretendida por toda a legislação e esperada

\footnotetext{
${ }^{5}$ Feminicídio é o homicídio praticado contra a vítima mulher por motivações baseadas em violência doméstica e/ou intrafamiliar, ou em caso de menosprezo ou discriminação pela condição de mulher. Lei.13/104 de 2015.
} 
pelo Estado, deixa de ser eficaz, porque a vítima se encontra sob a falsa segurança de que está salva e o Estado não possui um método eficiente de fiscalização após a decretação das medidas protetoras.

\section{CONCLUSÃO}

A Lei Maria da Penha se constitui um grande avanço na história da mulher, assim como um progresso social. As medidas protetivas de urgência são um marco significativo de prevenção contra a violência doméstica e familiar, e faz com que a conduta violenta seja repensada, ainda que não tenha surtido os efeitos esperados com a implementação, pois são necessários muitos ajustes para garantir eficácia, em todos os campos, legislativo, executivo e judiciário.

O Estado está se adaptando a uma legislação recente e também se modificando frente ao estigma cultural desenvolvido historicamente por um modelo machista advindo da dominação e da posse do homem sob a mulher. As mulheres carregam crenças e medos advindos deste sistema de dominação construído historicamente, em que a subjugação predomina frente aos direitos de uma vida livre de violência física, moral e psicológica.

Além disso, no campo da violência doméstica e familiar contra a mulher, a insegurança de que o Estado não conseguirá atuar com a urgência necessária para impedir a conduta violenta ou uma nova agressão, após o registro de ocorrência, encontra-se presente no dia a dia das vítimas. As angústias e o medo de perder a vida são constantes em muitas mulheres. Tais reflexos ficaram ainda mais evidentes neste período desafiador de isolamento em razão da Pandemia de Covid-19.

Assim, nesta pesquisa, buscou-se demonstrar a ineficácia das medidas protetivas de urgência no âmbito da violência doméstica, sob a problemática da falta de estrutura e amparo após a decretação destas medidas, que tornam as vítimas ainda mais vulneráveis. De fato, observa-se uma lógica de violência continuada por parte dos agressores, a partir dos estudos realizados no âmbito da Quarta Colônia, situada na Região Central do Estado do Rio Grande do Sul.

Os resultados obtidos foram significativos, mostrando que a violência doméstica e familiar é um assunto atual e bastante presente na vida das mulheres. Muitas relataram terem sofrido violência por parte de seus companheiros, namorados e esposos, mas que não realizaram a denúncia por medo de sofrerem represálias. Ainda, a violência psicológica se mostrou em evidência frente às demais violências praticadas contra as mulheres, sendo resultado de uma agressão que não deixa marcas na pele, mas acaba por destruir a alma. Nestes casos, se tem uma ofensa mascarada, com a desculpa de manter os bons costumes, como a falta de liberdade e de instrução aprisionaram as mulheres, por muito tempo.

Por fim, ressalta-se que apesar de avanços socioculturais e jurídicos conquistados pela mulher ao longo da história, sobretudo, após as conquistas dos movimentos feministas, esta ainda vive sob os resquícios de um modelo de sociedade patriarcal, que influencia na decisão de denunciar ou não 
o agressor. As medidas protetivas de urgência acabam oferecendo uma falsa segurança e uma ilusão de proteção às vítimas a partir dos estudos demonstrados e a violência continuada é maquiada pelas subnotificações.

\section{REFERÊNCIAS}

BERTOTTI, Bárbara Mendonça et al. (Org.). Gênero e resistência, volume 1: memórias do II encontro de pesquisa por/de/sobre mulheres [recurso eletrônico]. Porto Alegre, RS: Editora Fi, 2019. E-book (572 p.). ISBN -978-85-5696-524-0. Disponível em: https://bit.ly/2MZblTd. Acesso em: 30 set. 2020.

BERTOTTI, Bárbara Mendonça et al. (Org.). Gênero e resistência, volume 2: memórias do II encontro de pesquisa por/de/sobre mulheres [recurso eletrônico]. Porto Alegre, RS: Editora Fi, 2019. E-book (525 p.). ISBN -978-85-5696-525-7. Disponível em: https://bit.ly/3sjMQQU. Acesso em: 30 set. 2020.

BIAGI, Sandra Fernandes. Lei Maria da Penha: A aplicabilidade das Medidas Protetivas de Urgência como instrumento de prevenção e combate à reincidência. Trabalho de Conclusão de Curso (Especialização em Gestão de Políticas Públicas em Gênero e Raça - GPPGeR) - Universidade de Brasília - UnB, Faculdade de Educação, Brasília, 2014. Disponível em: https://bit.ly/3qeKjWk. Acesso em: 05 maio 2020.

BRASIL. Fórum Brasileiro de Segurança Pública. Anuário Brasileiro de Segurança Pública 2019. Disponível: https://bit.ly/2LMQMsn. Acesso em: 05 out. 2020.

BRASIL. Decreto-lei no 3.689, de 3 de outubro de 1941. Código de Processo Penal. Brasília, DF: Presidência da República, 1941. Disponível em: https://bit.ly/38Bmu4Y. Acesso em: 21 ago. 2020.

BRASIL. Lei no 11.340, de 7 de agosto de 2006. Cria mecanismos para coibir a violência doméstica e familiar contra a mulher, nos termos do $§ 8^{\circ}$ do art. 226 da Constituição Federal, da Convenção sobre a Eliminação de Todas as Formas de Discriminação contra as Mulheres e da Convenção Interamericana para Prevenir, Punir e Erradicar a Violência contra a Mulher; dispõe sobre a criação dos Juizados de Violência Doméstica e Familiar contra a Mulher; altera o Código de Processo Penal, o Código Penal e a Lei de Execução Penal; e dá outras providências. Brasília, DF: Presidência da República, 2006. Disponível em: https://bit.ly/39s5rRV. Acesso em: 05 maio 2020.

CARNEIRO, Alessandra Acosta; FRAGA, Cristina Kologeski. A Lei Maria da Penha e a proteção legal à mulher vítima em São Borga no Rio Grande do Sul. Serviço Social \& Sociedade, São Paulo, n. 110, p. 369-397, abr.jun. 2012. Disponível em: https://bit.ly/2LnG8Zi. Acesso em: 16 maio 2020. 
CAVAlCANTE, Caio César Claudino; RESENDE, Gisele Silva Lira de. A lei Maria da Penha e a Rede de Enfrentamento à Violência Contra a Mulher no município de Barra do Garças-MT. Revista FACISA $\boldsymbol{O N}-\boldsymbol{L I N E}$, vol. 3, n. 3, 2014. Disponível em: https://bit.ly/3qjuIox. Acesso em: 29 ago. 2020.

COSTA, Cibelle Tiphane de Sousa; OLIVEIRA, Eliany Nazaré; COSTA, Silvinha de Sousa; FÉLIX, Tamires Alexandre; ELOIA, Suzana Mara Cordeiro; SANTOS, Francisco Diogenes dos. Violência Contra a Mulher: fatos e contextos de boletins de ocorrências. 2014. Tempus, actas de saúde coletiva. Brasília, v. 8, n. 4, p. 177-188, 2014. Disponível em: https://bit.ly/2LMFbJO. Acesso em: 27 jun. 2020.

CUNHA, Barbara Madruga da. Violência contra a mulher, direito e patriarcado: perspectiva de combate à violência de gênero. In: XVI Jornada de Iniciação Científica de Direito da UFPR, 2014, Paraná: UFPR. Anais eletrônicos da XVI Jornada de Iniciação Científica de Direito da UFPR. Paraná: UFPR, 2014. Disponível em: https://bit.ly/3oGE1y8. Acesso em: 15 out. 2020.

DAHL, Tove Stang $\mathbf{O}$ direito das mulheres: uma introdução à teoria do direito feminista.Trad. Teresa Beleza et al. Fundação Calouste Gulbenkian: Lisboa, 1993.

MOURA, Maria de Jesus Pereira. Natureza jurídica e efetividade das medidas protetivas de urgência da lei $n^{\circ}$ 11.340/06 (Lei Maria da Penha), no enfrentamento da violência doméstica e familiar contra a mulher. Trabalho de Conclusão de Curso (Graduação em Direito) - Faculdade de Direito, Universidade Federal do Ceará, Fortaleza, 2015. Disponível em: https://bit.ly/35xJmk0. Acesso em: 29 set. 2020.

PALACIO, Nicolasa María Durán. La ética del cuidado: uma voz diferente. Revista Fundación Universitaria Luis Amigó. v. 2. n. 1. Medellín - Colombia: enero-junio, 2015, p. 12-21.

PASINATO, Wânia; GARCIA, Isis de Jesus; VINUTO, Juliana; SOARES, Jenefer Estrela. 7 Medidas Protetivas para as Mulheres em Situação de Violência. In: PARESCHI, Carolina Cambreses; ENGEL, Cíntia Liara; BAPTISTA, Gustavo Camilo. Direitos Humanos, Grupos Vulneráveis e Segurança Pública. [recurso eletrônico]. Brasília: Ministério da Justiça e Cidadania, Secretaria Nacional de Segurança Pública, 2016. p. 233-265. Ebook (302 p.). (Coleção Pensando a Segurança Pública, Volume 6). Disponível em: https://bit.ly/2Ljd2KS. Acesso em: 27 set. 2020.

RÉGES, Aline; CORDEIRO, Euller Xavier. A ineficácia das medidas protetivas de urgência na lei Maria da Penha. Trabalho de Conclusão de Curso (Bacharelado em Direito) - Centro Universitário Toledo, Araçatuba, 2015. Disponível em: https://bit.ly/2LJYaVq. Acesso em: 17 maio 2020. 
SABADELL, Ana Lúcia. Isolamento e a privacidade "tóxica" em tempos de pandemia: o sofrimento feminino. Boletim Ibccrim. Ano 28, n. ${ }^{\circ}$ 330, Boletim especial Lei anticrime, Maio de 2020. Disponível em: https://bit.ly/3sgIBpd. Acesso em: 03 dez. 2020.

SALGADO, Eneida Desiree; KREUZ, Letícia Regina Camargo; BERTOTTI, Bárbara Mendonça (Org.). Mulheres por mulheres: memórias do I Encontro de Pesquisa por/de/sobre Mulheres [recurso eletrônico]. Porto Alegre, RS: Editora Fi, 2018. E-book(472 p.). Disponível em: https://bit.ly/3oGEdgQ. Acesso em: 30 set. 2020.

VASCONCELOS, Claudivina Campos; RESENDE, Gisele Silva Lira de. VIOLÊNCIA DOMÉSTICA: A Aplicabilidade e Eficácia das Medidas Protetivas como Instrumento de Prevenção e Combate à Reincidência na Comarca de Barra do Garças-MT. Revista Direito em Debate, v. 27, n. 49, ago. 2018, p. 117-137. Disponível em: https://bit.ly/39nXxcy. Acesso em: 27 set. 2020. 
